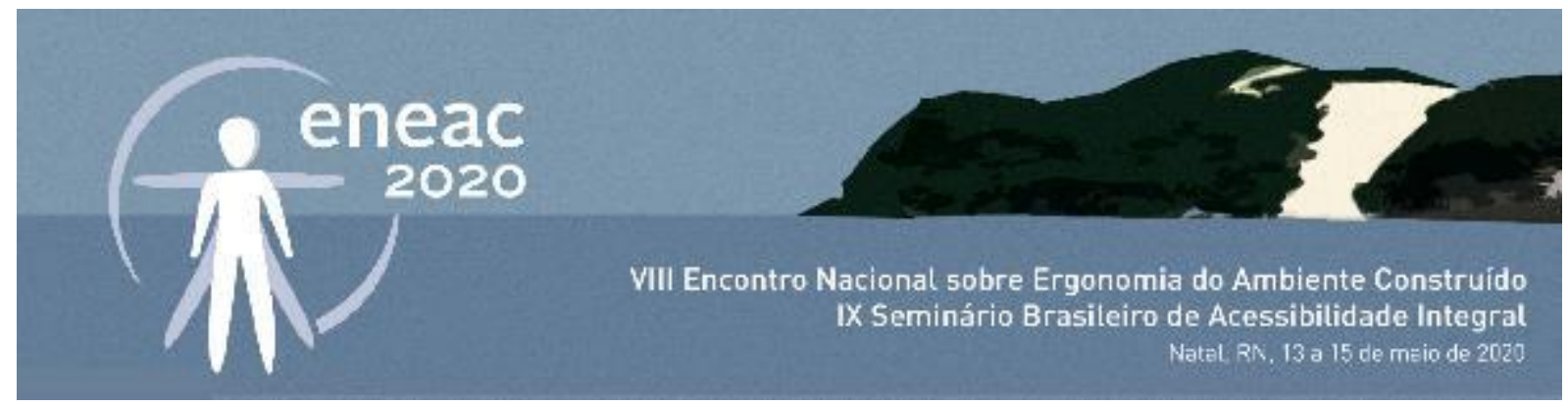

\title{
Análise das condições de acessibilidade em estádio de futebol brasileiro
}

\section{Accessibility conditions analysis in a brazilian soccer stadium}

\author{
LÁZARO AIRES PEREIRA
}

Bacharel em Engenharia de Produção, Universidade Federal de Pelotas, lazaroairespereira@gmail.com

ITALO RODEGHIERO NETO

Doutorando em Engenharia de Produção, Universidade Federal do Rio Grande do Sul,

italorneto@gmail.com

MAYARA ZANCHIN

Mestre em Ciência, Universidade Federal de Pelotas, maayfrizzo@gmail.com

LUIS ANTONIO DOS SANTOS FRANZ

Doutor em Engenharia de Produção, Universidade Federal de Pelotas, luizfranz@gmail.com

ISABELA FERNANDES ANDRADE

Doutora em Arquitetura e Urbanismo, Universidade Federal de Pelotas, acessiarq@gmail.com

\section{RESUMO}

A pessoa com deficiência é toda aquela que possui impedimentos de natureza física, intelectual ou sensorial, dificultando sua participação na sociedade. Por meio da acessibilidade é possível a realização de atividades e uso dos espaços por qualquer pessoa, com conforto, segurança e autonomia. O presente estudo visa avaliar as condições de acessibilidade no estádio de futebol da Boca do Lobo, localizado na cidade de Pelotas, identificando problemas de acessibilidade espacial no estabelecimento e propondo melhorias para tornar o local acessível a todos os usuários. A análise foi realizada meio de visita exploratória, com a aplicação das Planilhas de Acessibilidade. A partir destas, foi possível avaliar os três portões de acesso do estádio, bem como seus caminhos internos para a circulação horizontal e vertical, os sanitários e as arquibancadas, identificando seus aspectos positivos e negativos. Ao final da análise, percebeu-se que as condições de acessibilidade do estabelecimento não garantem que todas as pessoas consigam utiliza-lo de forma autônoma e segura. Para isto, são sugeridas reformas, como a retirada dos desníveis dos sanitários e rampas e, principalmente, a garantia de acesso por todos os usuários nas entradas do estádio.

PALAVRAS-CHAVE: Acessibilidade, estádio de futebol, visita exploratória, visão técnica frente ao espaço 


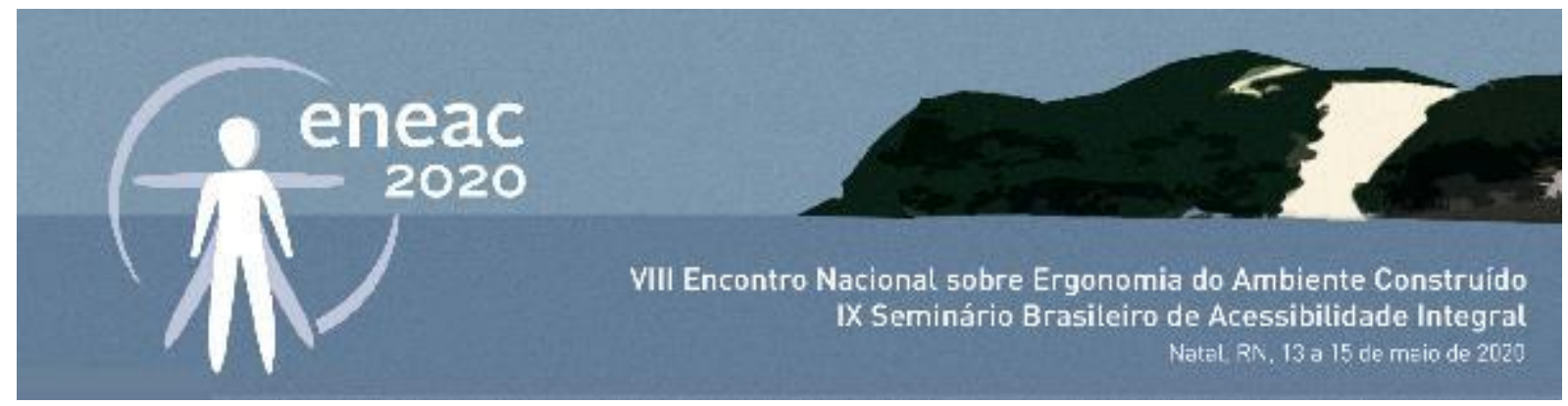

\begin{abstract}
A person with a disability is anyone who has physical, intellectual or sensory impairments, making it difficult for them to participate in society. Through accessibility it is possible to carry out activities and use of spaces by anyone, with comfort, safety and autonomy. This study aims to assess the accessibility conditions at the Boca do Lobo football stadium, located in the city of Pelotas, identifying problems of spatial accessibility in the establishment and proposing improvements to make the place accessible to all users. The analysis was carried out through an exploratory visit, with the application of the Planilhas de Acessibilidade. From these, it was possible to evaluate the three access gates of the stadium, as well as their internal paths for horizontal and vertical circulation, the toilets and the bleachers, identifying their positive and negative aspects. At the end of the analysis, it was noticed that the accessibility conditions of the establishment do not guarantee that all people will be able to use it in an autonomous and safe way. For this, reforms are suggested, such as the removal of the unevenness of the toilets and ramps and, mainly, the guarantee of access by all users at the stadium's entrances.
\end{abstract}

KEYWORDS: Accessibility, soccer stadium, exploratory visit, technical vision in front of the space

\title{
1 INTRODUÇÃO
}

Conforme explicado por Silva et al. (2019), entende-se que pessoa com deficiência é aquela que tem impedimentos de natureza física, intelectual ou sensorial. Estes impedimentos podem restringir a participação plena e efetiva com as demais pessoas, quando em interação com diversas barreiras.

Para atender à todas as pessoas, independente de suas características, Andrade (2016) apresenta a acessibilidade como "a possibilidade de realização de atividades e uso dos espaços por qualquer pessoa, com conforto, segurança e independência". Trata-se de um direito civil básico e todos os mecanismos que assegurarem a sua implementação devem ser aplicados, apesar de uma grande parte da população ainda estar longe de utilizar todos os espaços (SANTOS et al., 2017, VAN WEE, 2016).

Os conceitos que cercam a acessibilidade são diversos, como o de acessibilidade plena, universal e espacial. Para fins deste trabalho, será dada ênfase ao conceito de acessibilidade espacial, conforme Dischinger, Bins Ely e Piardi (2012), “[...] atingir um lugar desejado, e que este permita ao usuário compreender sua função, sua organização e relações espaciais, assim como participar das atividades que ali ocorrem.".

As autoras classificam os componentes de acessibilidade em quatro categorias: orientação espacial, comunicação, deslocamento e uso, sendo que cada um destes é formado por um conjunto de diretrizes, garantindo o acesso as pessoas com deficiências em determinados ambientes ao tentar minimizar as restrições espaciais (DISCHINGER, BINS ELY e PIARDI, 2012). Portanto, a acessibilidade espacial está relacionada aos cumprimentos desses quatro componentes em sua totalidade.

No Brasil, o futebol é o esporte mais difundido e o que tem o maior número de espectadores. Sendo assim, o estádio de futebol deve estar apto a receber todas as pessoas, pois trata-se de um ambiente complexo em que gestores devem garantir a utilização do diverso público de torcedores, que pode 


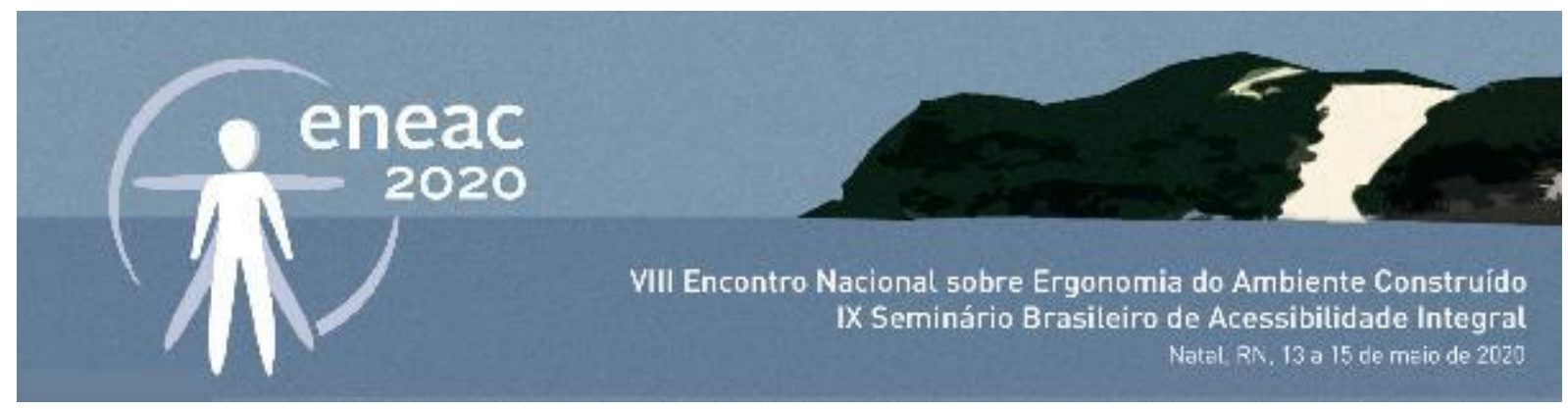

contar também com pessoas em cadeiras de rodas, obesos e idosos (ENSSLIN, ENSSLIN e PACHECO, 2012; PARAMIO-SALCINES et al., 2018).

Yazigi et al. (2015) complementa que, para que estes espaços possam ser alcançados e utilizados por todas as pessoas, é necessária a consideração dos parâmetros de acessibilidade em projetos de novas instalações e, também, nas reformas de estádios já existentes. Isto vai de encontro com o projetado no passado, pois os estádios eram construídos sem levar em consideração as questões de acessibilidade espacial (BROMBILLA, 2014).

A Lei № 10.671 de 15 de maio de 2003, dispõe sobre o Estatuto de Defesa do Torcedor e dá outras providências, sendo aqui assegurado condições de acessibilidade ao torcedor com deficiência ou mobilidade reduzida e o direito a implementação de planos de ação referentes à segurança, transporte e contingência que possam ocorrer durante a realização de eventos esportivos, atendendo as questões vinculadas a Norma Brasileira de Acessibilidade (9050/2015).

Posto isso, o trabalho teve como objetivo avaliar as condições de acessibilidade no estádio de futebol da Boca do Lobo, localizado na cidade de Pelotas - RS. Por meio do método Visita Exploratória e pela aplicação das Planilhas de Acessibilidade desenvolvidas por Dischinger, Bins Ely e Piardi (2012), espera-se identificar potencialidades e desconformidades relacionados a acessibilidade espacial nos espaços do ambiente a ser analisado e, assim, propor melhorias para tornar o local acessível a todos os usuários.

\section{METODOLOGIA}

Primeiramente, no intuito de se obter conhecimento técnico a respeito de conceitos e da legislação vigente, realizou-se uma revisão bibliográfica. Para isto, pesquisou-se em artigos e livros relacionados à área, além da Norma Brasileira de Acessibilidade - 9050 (2015). Por fim, buscou-se identificar uma metodologia que contemplasse a investigação de condições da acessibilidade no ambiente estudado. A partir disso, foi definido que se trabalharia com o método denominado visita exploratória.

\subsection{VISITA EXPLORATÓRIA}

A visita exploratória consiste em um método que auxilia a análise da funcionalidade do ambiente construído no primeiro contato com o avaliador e o usuário. De acordo com Gosling et al. (2016), a experiência dos visitantes não é estática, mas sim um processo dinâmico que envolve o antes, o durante e o depois da visita, resultando de interações que são influenciadas por diferentes contextos.

Rodeghiero Neto et al. (2020) traz que quando esta metodologia é aplicada corretamente, permite-se um comparativo entre as questões encontradas com as normas e legislações vigentes com o ambiente, identificando as suas potencialidades e desconformidades.

As visitas exploratórias devem ser utilizadas em conjunto às técnicas de observação do ambiente, facultada a realização de levantamentos métricos e fotográficos e o preenchimento de informações em planilhas. Isto tem a finalidade de se obter a visão técnica frente ao objeto de estudo. Para a sistematização dos dados, foram utilizadas as planilhas de acessibilidade desenvolvidas por Dischinger, Bins Ely e Piardi (2012). 


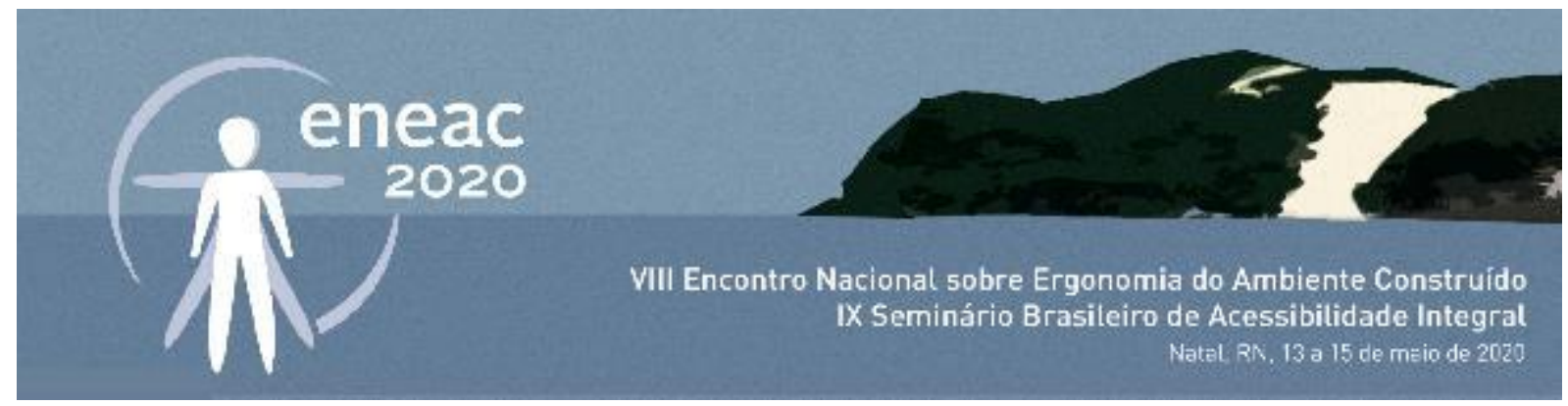

\subsection{PLANILHAS DE ACESSIBILIDADE}

As planilhas de acessibilidade foram ordenadas conforme o encaminhamento do usuário ao longo do edifício, desde sua chegada - a partir da via pública - até a realização de suas atividades de interesse (DISCHINGER, BINS ELY e PIARDI, 2012). Num total de seis, as planilhas abordam "Área de acesso ao edifício"; "Saguões, salas de recepção e espera"; "Circulações horizontais"; "Circulações verticais"; "Sanitários" e "Locais de atividades coletivas" (Figura 1).

Figura 1: Recorte exemplificando a planilha de acessibilidade (Planilha 1)

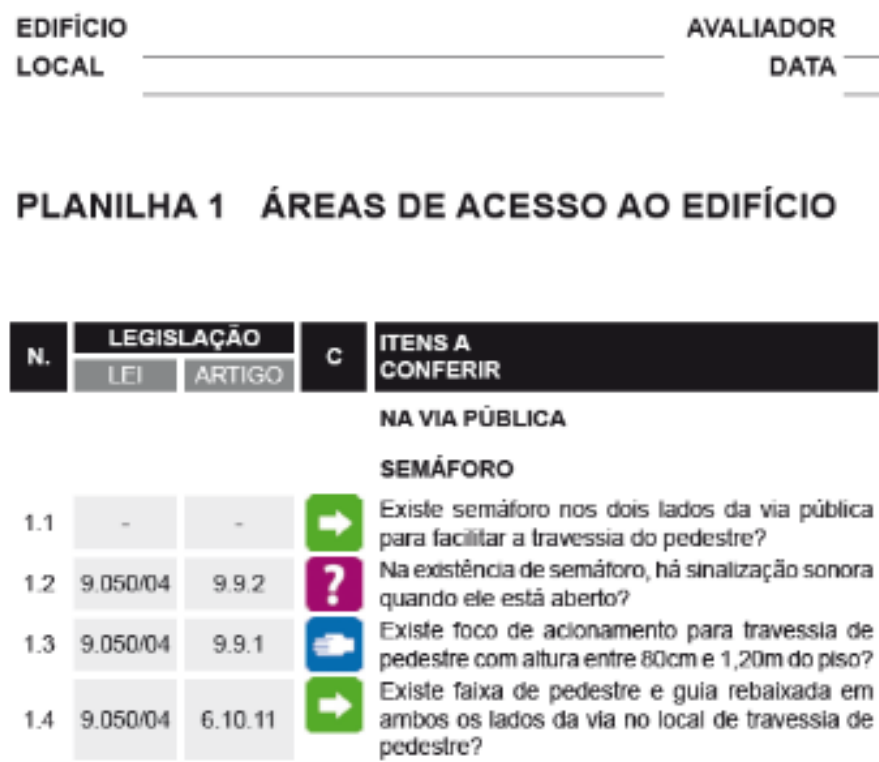

Fonte: Dischinger, Bins Ely e Piardi (2012).

Este instrumento de coleta de dados está estruturado em seis colunas: número identificador, que relaciona a planilha e o item a ser conferido; a legislação, contemplando o número da Norma ou lei que está sendo analisada; os componentes de acessibilidade espacial que é observado pelo item, representado por imagens; itens a conferir, com a descrição do que está sendo analisado e, por fim, as colunas de resposta e observações, que devem ser preenchidas pelo avaliador.

Para Pinto e Dorneles (2018), a divisão dos itens nos quatro componentes da acessibilidade garantem uma completa análise da legislação, facilitando no momento da proposição de melhoria dos ambientes estudados. No estudo foram utilizadas as planilhas 1, 3, 4, 5 e 6 . A planilha 2 não foi adotada tendo em vista que o ambiente analisado não possui salas de espera e/ou saguões.

\subsection{OBJETO DE ESTUDO}

O objeto de estudo escolhido se trata do Estádio da Boca do Lobo, situado na cidade de Pelotas, Rio Grande do Sul, Brasil. Este estádio de futebol foi fundado no ano de 1908, após a fusão de dois times de futebol da cidade, dando origem ao Esporte Clube Pelotas. Tendo passado por três reformas desde 


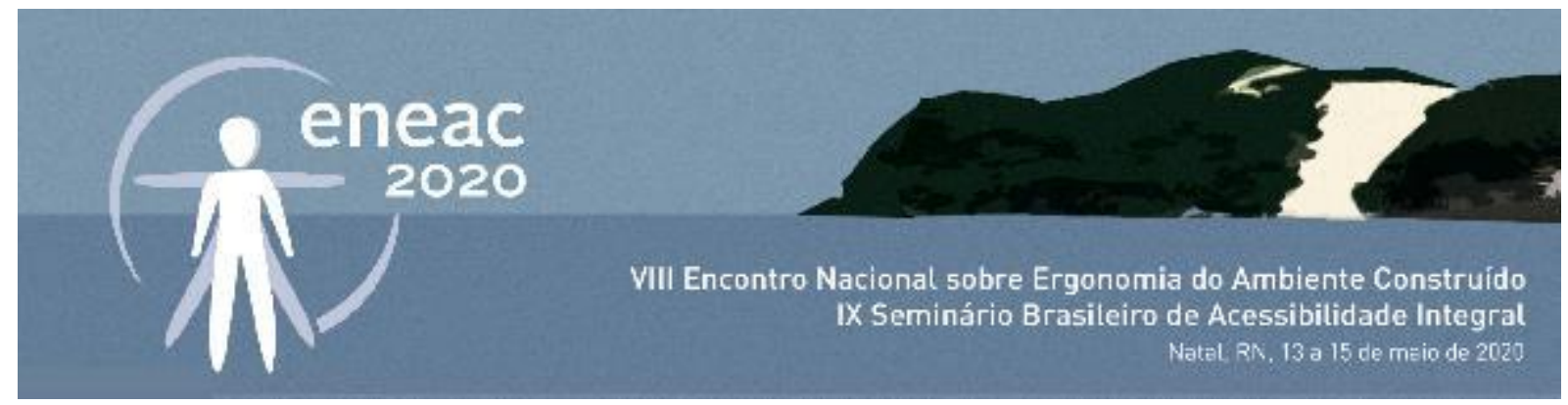

a data de lançamento, o ambiente teve sua última modificação estrutural no ano de 2002, ao ser construída uma nova arquibancada, fazendo com que sua capacidade de público chegasse a 25.000 espectadores.

Atualmente, além das partidas do clube de futebol, o estádio abriga eventos culturais e religiosos da cidade. Hoje, segundo o Esporte Clube Pelotas (2018) a Boca do Lobo é o estádio mais antigo do país em atividade.

\section{RESULTADOS E DISCUSSÃO}

Foram realizadas duas visitas exploratórias no local. A primeira para ter uma visão geral do local, sem aplicação de técnicas e, na segunda visita foi aplicada a planilha de acessibilidade associada a levantamentos métrico e fotográfico.

O edifício possui cinco acessos a partir da via pública, porém, somente três são utilizados durante as partidas de futebol realizadas no local. Dessa forma, foram analisadas estas três entradas, aplicandose a planilha 1 a cada um dos três acessos existentes.

A Planilha 1 (Áreas de acesso ao edifício) é dividida em três itens principais de análise: semáforo, passeios e circulação. Referente ao Acesso 1 (Rua Gonçalves Chaves) o deslocamento torna-se restrito, pois não existe faixa de pedestre, guia rebaixada ou semáforo para facilitar a travessia do pedestre em ambos os lados da via. Com a falta de um semáforo, outros componentes da acessibilidade como sinalização sonora para semáforo aberto (orientação) bem como o acionamento para travessia de pedestres (uso) não são aplicados. Pela Figura 2, pode-se observar o exterior e o interior, respectivamente, do Acesso 1 ao estádio.

Figura 2: Exterior e interior do Acesso 1 ao estádio Boca do Lobo

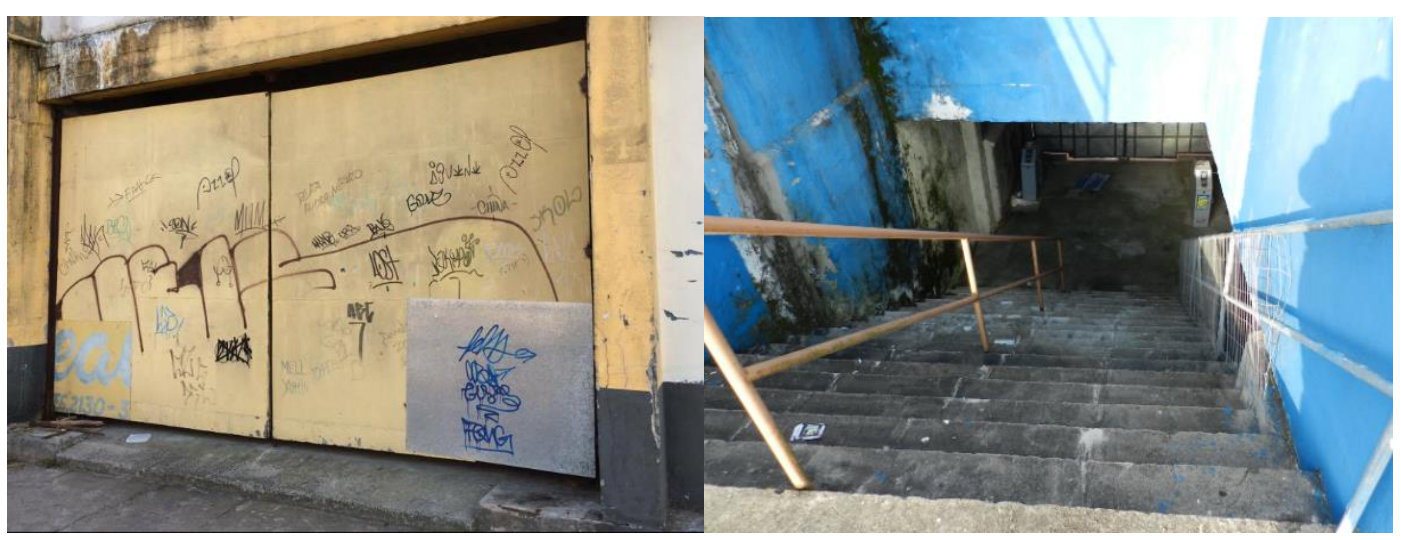

Fonte: Autores (2019).

No Acesso 2 (Avenida Bento Gonçalves) percebe-se a existência de semáforos dos dois lados da via, bem como guia rebaixada e faixa de pedestres para facilitar na travessia. Entretanto, mesmo com a existência de semáforos, esses não contam com botão de acionamento para travessia de pedestres ou sinalização sonora para semáforo aberto. 


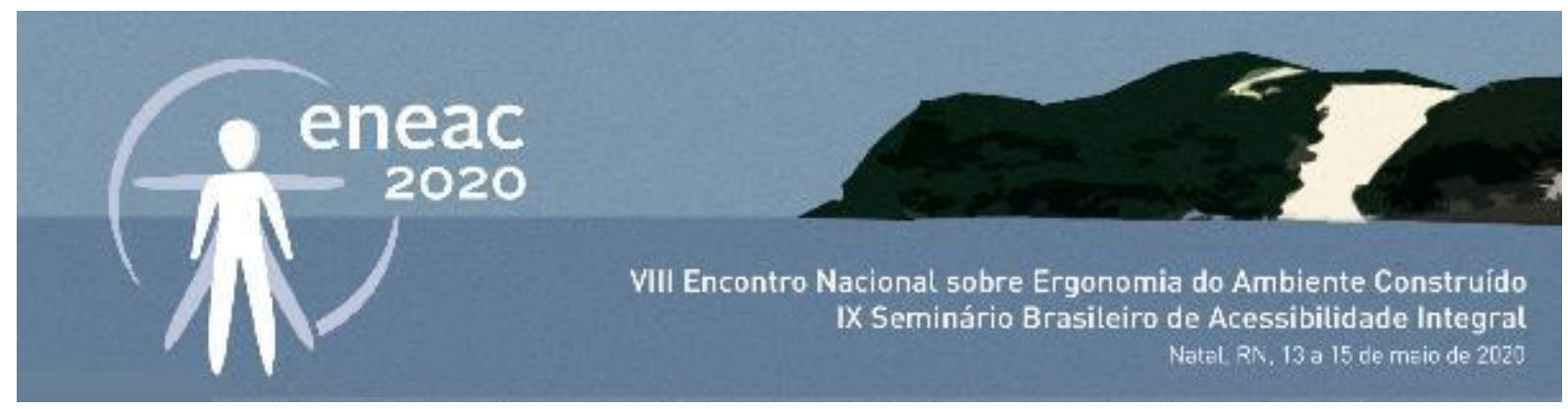

Por fim, no Acesso 3 (Rua Padre Anchieta), que possui duas portas de entrada com $170 \mathrm{~cm}$ de largura cada, não foram encontrados semáforos ou faixas de segurança para o transporte de pedestres. Assim, os quatro componentes da acessibilidade ficam comprometidos, visto que não existem as condições necessárias para o trânsito seguro das pessoas.

A partir da análise efetuada nos três acessos, pode-se observar que todas estas possuem passeios com $180 \mathrm{~cm}$, pisos antiderrapantes e desníveis inferiores a 1,5 cm, conforme solicitado pela Norma Brasileira de Acessibilidade. Os acessos de entrada ao edifício público nos locais de análise 1 e 2 constituem uma rota livre de obstáculos, com largura maior que 120 centímetros, conforme Figura 3.

No entanto, não apresentam sinalização tátil (alerta ou direcional) para que possa identificar o caminho livre de obstáculos. Ainda, não foi encontrada sinalização de alerta para obstáculos como postes, placas de sinalização e falhas nas calçadas, se tornando um indício de perigo para as pessoas com deficiência visual.

O Acesso 3 apresenta todos os problemas evidenciados nos outros dois acessos. Contudo, é possível observar que a largura dos seus passeios é de $180 \mathrm{~cm}$ (sendo superior ao mínimo exigido por lei - 120 $\mathrm{cm}$ ). Além disso, este é o único acesso que possui identificação do estádio, indicando o nome do estádio e do clube através de pinturas. Ainda assim, seu acesso às arquibancadas se dá por escadas, dificultando ou impedindo que pessoas com deficiência e/ou mobilidade reduzida utilizem de todas as dependências.

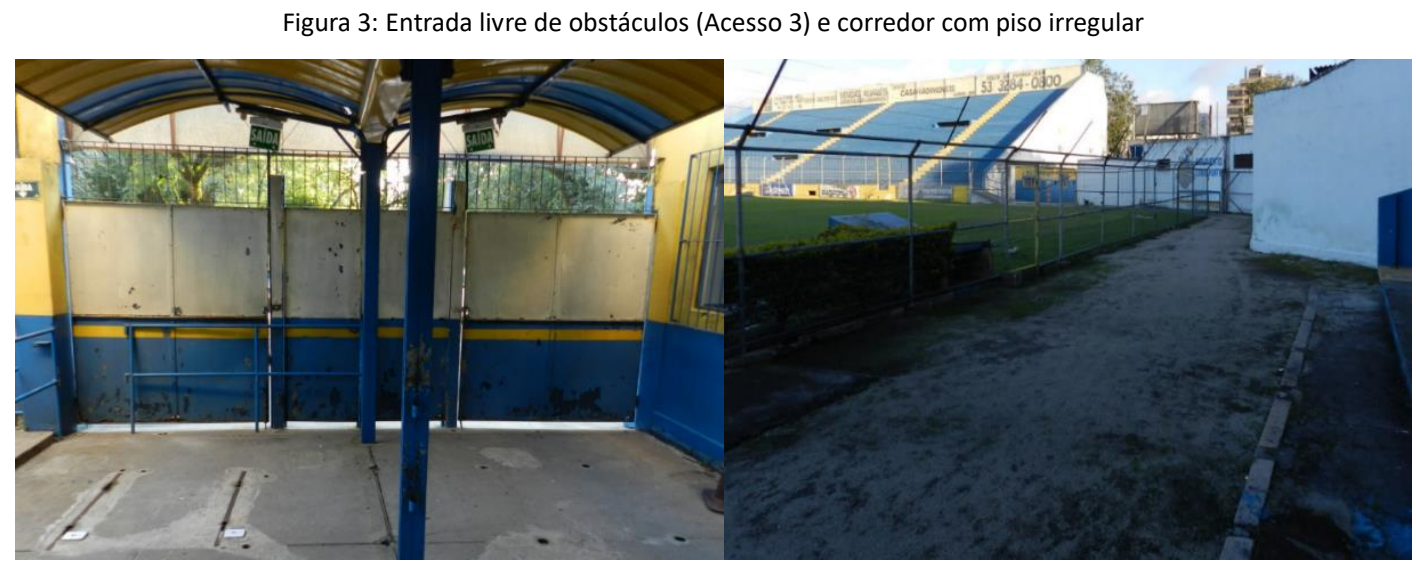

Fonte: Autores (2019).

Em relação à Planilha 3 (Circulação horizontal), foi verificado que o estádio possui os corredores com dimensões em conformidade com a NBR 9050 (2015), tendo largura mínima de 90 centímetros (quando sua extensão for de até 400 centímetros), 120 centímetros de largura (quando sua extensão for de até 1000 centímetros) e largura de 150 centímetros (quando sua extensão for maior que 1000 centímetros) - com uma faixa livre de obstáculos e sem a presença de lixeiras, telefones públicos ou extintores de incêndio obstruindo a passagem.

Seus corredores possuem largura mínima de 90 centímetros sem obstáculos e seu piso é antiderrapante e firme quase em sua totalidade. Porém, há locais onde o piso é irregular, não antiderrapante e desnivelado (Figura 3). Os corredores não possuem sinalização suspensa para saídas 


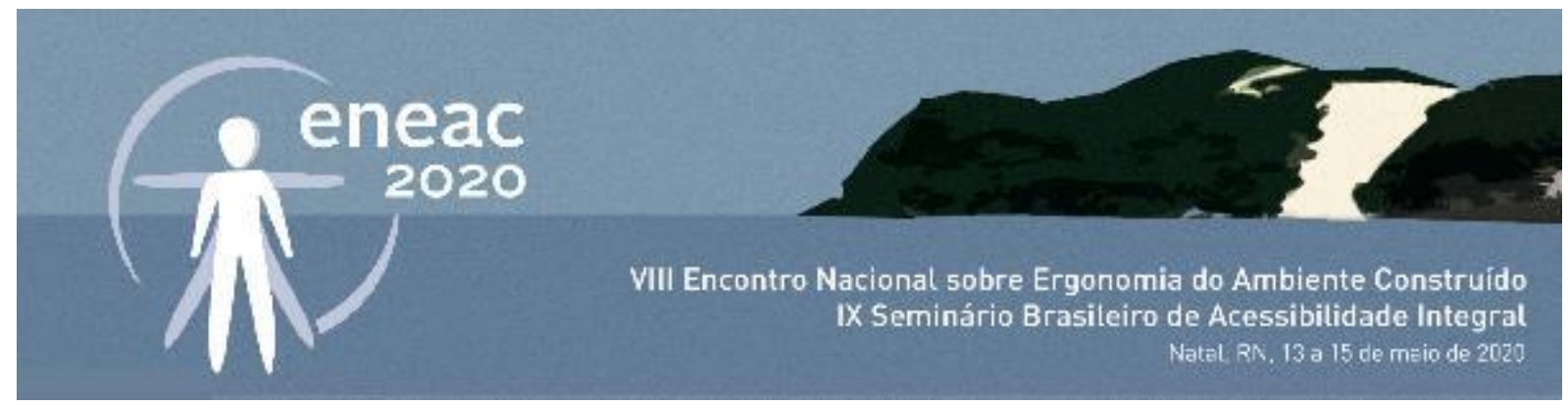

de emergência ou sistema de alarme de incêndio simultaneamente sonoro e luminoso em caso de situações de emergência.

$\mathrm{Na}$ aplicação da Planilha 4 (Circulação vertical), no que se refere às escadas, identificaram-se escadas em dois dos três acessos do estabelecimento, como já indicado anteriormente, ambas com largura mínima de $120 \mathrm{~cm}$ e construídas em material incombustível (concreto) e antiderrapante. Os degraus são paralelos e possuem entre 28 e 32 centímetros de profundidade (base) com lance máximo de 19 degraus - conforme legislação vigente (Figura 4).

Os degraus apresentam os espelhos vazados, o que não está em conformidade com a NBR 9050 (2015). Contudo, há corrimãos instalados em ambos os lados da escada mas não possuem prolongamento mínimo de 30 centímetros antes do início do lance de degraus e após o seu término conforme indicado pela legislação - e não há sinalização tátil de alerta no início e no término da escada. Em todos os acessos, o guarda-corpo possui altura mínima de 105 centímetros, com sinalização visual localizada na borda do piso, bem como sistema de iluminação emergencial no corpo da escada.

Figura 4: Rampas de acesso do estádio

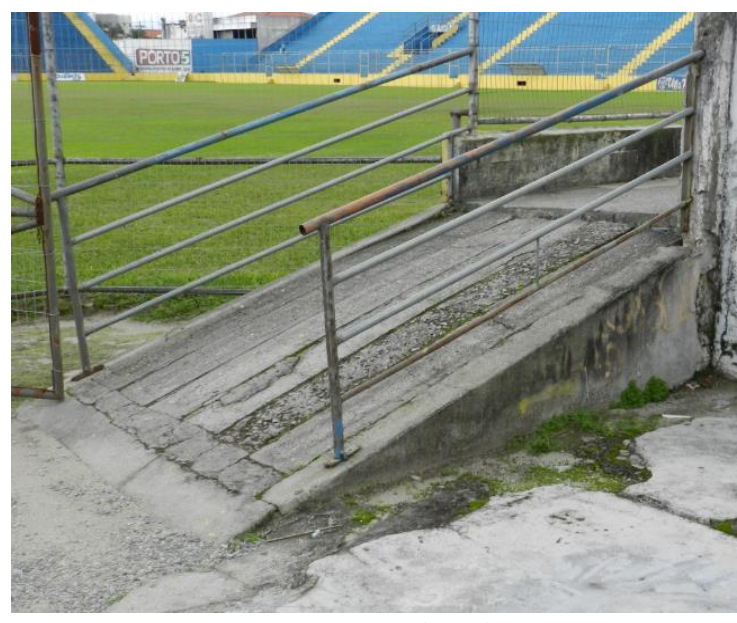

Fonte: Autores (2019).

No edifício também há uma rampa de acesso (Figura 4) medindo 200 × 300 × 80 centímetros e seu piso é antiderrapante e firme. Porém, há um degrau de cinco centímetros antes de seu término, o que limita o seu uso por todos os indivíduos que frequentam o estabelecimento.

Os corrimãos estão instalados em ambos os lados da rampa a uma altura de 92 centímetros e possuem largura de quatro centímetros - estando de acordo com a norma; porém, suas extremidades não são curvas e terminam antes do início e do final da rampa. Não existe sinalização tátil de alerta no início e no término da rampa. Além disso, sua inclinação é de $26,6 \%$, o que está em desconformidade com o item 6.6.2.1 da NBR 9050 (2015) que prevê uma inclinação máxima para rampas, após reformas, de $12,5 \%$.

A partir da quinta planilha, foi possível analisar as condições dos sanitários no objeto de estudo. Não existe um conjunto de sanitários - masculino e feminino - acessíveis para as pessoas com deficiência. 


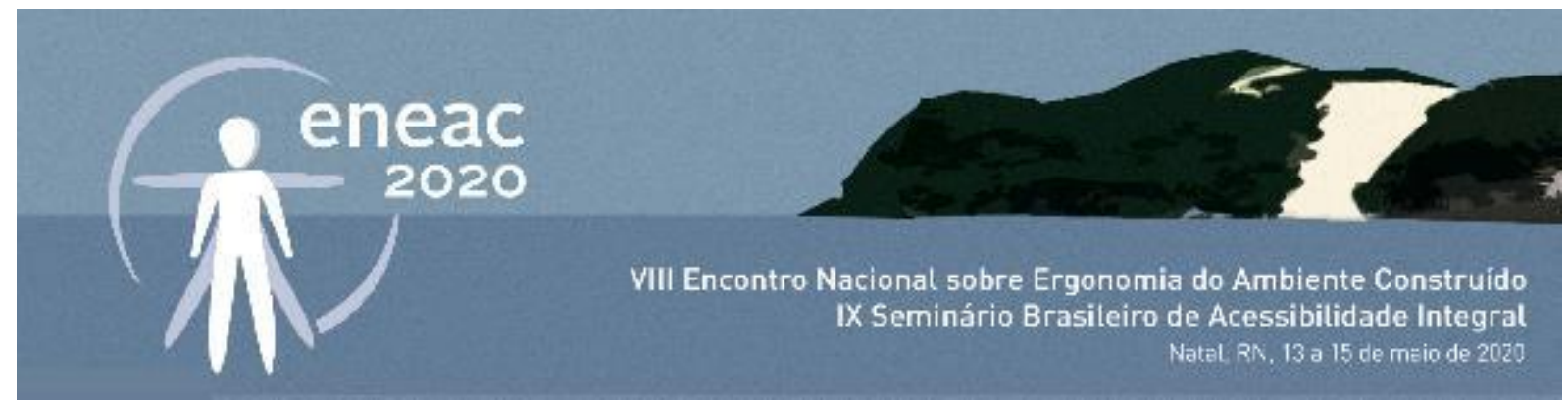

Apesar da existência de banheiros disponíveis ao público no ambiente, estes espaços não possuem sinalizações visuais, como símbolos e textos, ou táteis, como figuras em alto relevo ou em Braille, sendo um aspecto negativo relacionado à orientação espacial.

Mesmo estando em uma rota acessível, próximo à circulação principal, existe um degrau na entrada do sanitário com mais de $25 \mathrm{~cm}$, impedindo o acesso de pessoas com limitações físico-motoras, conforme mostrado na Figura 5. As maçanetas não foram adotadas conforme indica a Norma Brasileira de Acessibilidade (do tipo alavanca), não sendo garantido seu uso por todas as pessoas. Entretanto, o vão livre da porta é superior a $80 \mathrm{~cm}$ e a porta abre para fora, sendo esses aspectos positivos que devem ser destacados no que tange a acessibilidade.

Figura 5: Área externa e interna dos sanitários do estádio

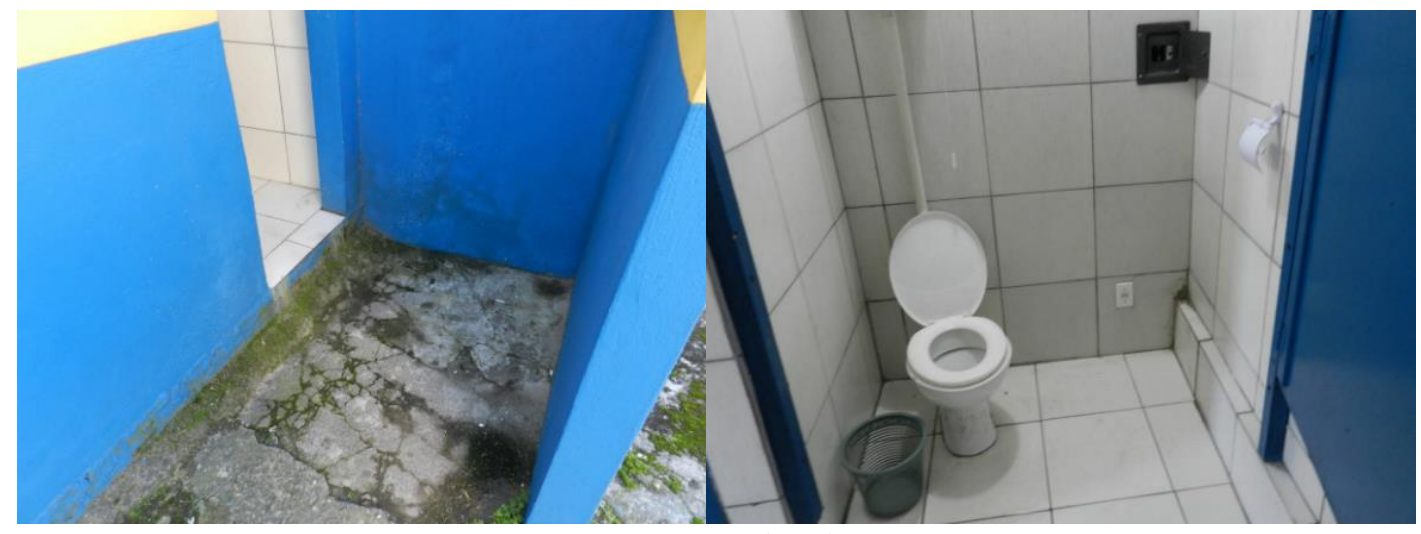

Fonte: Autores (2019).

No interior dos sanitários, as dimensões não estão de acordo com a NBR 9050 (2015). Apesar de possuir área livre de aproximação do sanitário, com piso antiderrapante, a altura do vaso sanitário e pia estão desconformes para a utilização por todas as pessoas, conforme destacado pela Norma.

Somado a isto, não há barras de apoio instaladas para a transição de uma pessoa com deficiência da cadeira de rodas ao vaso sanitário. Ainda, o sanitário possui uma área de manobra externa para mobilidade de um usuário em cadeira de rodas de $135 \times 90$ centímetros, quando a norma diz que o espaço deve ter, no mínimo, 150 × 150 centímetros. Na Figura 5 também pode ser observado o interior dos sanitários e os desníveis existentes.

Por fim, em relação aos locais para atividades coletivas, avaliou-se as questões de acessibilidade vinculadas aos espaços utilizados para assistir as partidas de futebol, como arquibancadas. Nestes ambientes existe pelo menos um espaço destinado às pessoas em cadeira de rodas (Figura 6), com dimensões de com $230 \times 180$ centímetros, ou seja, maior que o espaço indicado pela norma de acessibilidade. Entretanto, este espaço não está fora da área de circulação de pessoas e não está devidamente sinalizado para sua identificação. 

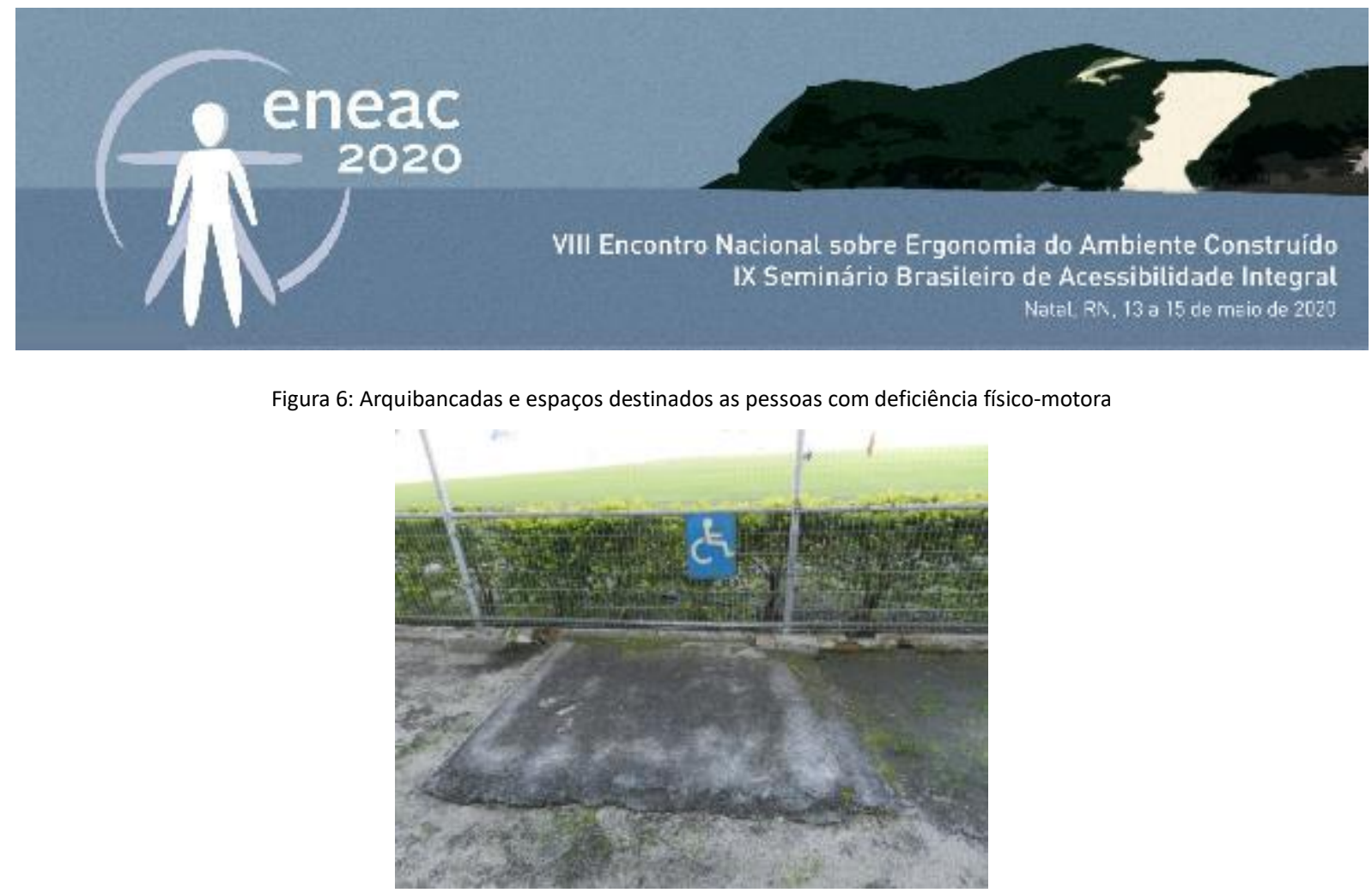

Fonte: Autores (2019).

As arquibancadas de concreto são destinadas ao público em geral e apresentam boa visualização do campo de jogo. A divisão destes espaços se dá apenas para sócios e não sócios. Com isto, não existe um espaço destinado unicamente a pessoas obesas ou pessoas com mobilidade reduzida.

Não foi possível, também, ser identificado sinalizações ou placas destinadas a comunicar à estas pessoas sobre os espaços. Ainda assim, cabe destacar que os assentos não são limitados, podendo ser utilizados com tranquilidade por estes indivíduos.

\section{CONCLUSÕES}

Após a análise dos resultados, é possível concluir que o estádio da Boca do Lobo, em Pelotas, não está de acordo com as legislações e normas vigentes relacionadas à acessibilidade. Levando em consideração que o Estádio tenha passado por reformas estruturais, a recente construção de uma nova arquibancada e, ainda, o prazo estipulado pelo decreto para a adaptação dos ambientes já ter sido encerrado, espera-se que os espaços nos dias de hoje sejam acessíveis à todas as pessoas.

Entretanto, após a aplicação das planilhas de acessibilidade, fica evidente que o local não garante a acesso seguro, confortável e autônomo, independente das suas condições. Assim, são necessárias intervenções para tornar-se, de fato, acessível.

Questões vinculadas aos acessos para o interior do estádio, dos quais são realizados por meio de escadas principalmente, é um dos principais pontos que são necessárias melhorias. Pela presença de desníveis e ausência de rampas, as pessoas com deficiência físico-motora não conseguem utilizar o local de modo independente.

Sugere-se também a alteração dos sanitários (tanto masculino quanto feminino) quanto a remoção de desníveis que dão acesso ao interior do sanitário, além de adaptações em seu interior, como a colocação de barras de apoio e a adequação de altura dos mobiliários.

As rampas existentes apresentam inclinação de $26,6 \%$, o que está em desconformidade com a legislação (máximo de 12,5\% de declive após reformas). Por fim, foi detectada a ausência de sinalização, para que as pessoas consigam se orientar no espaço. Para solucionar a questão, sugere-se 


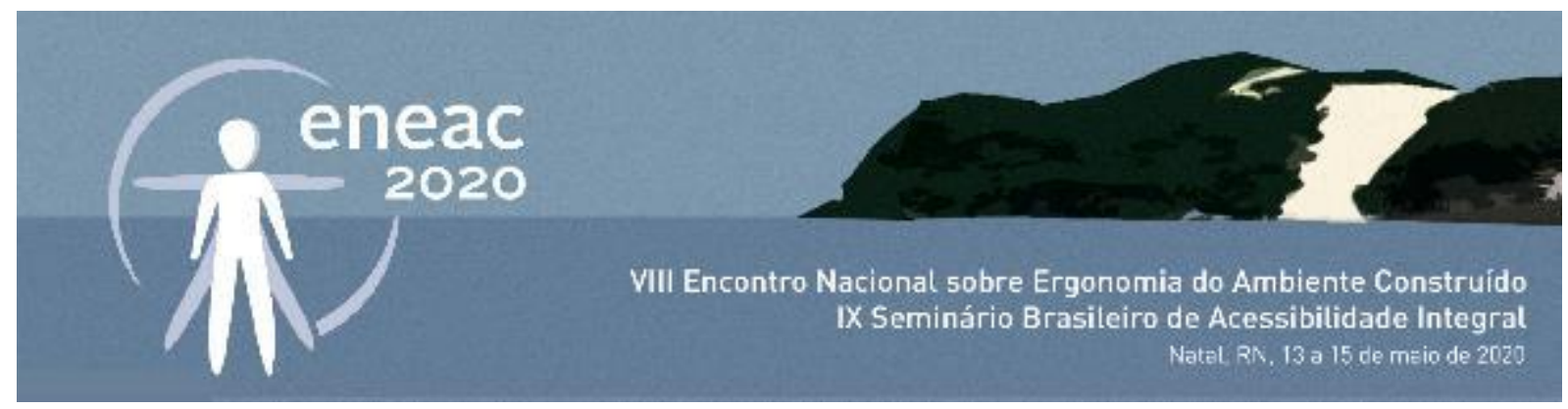

a colocação de placas e letreiros que indiquem as funções de cada ambiente.

Apesar de existirem pontos considerados como acessíveis, como rampas e espaços destinados às pessoas com deficiência para assistirem aos jogos, as condições ainda são precárias. Portanto, não pode ser garantido, sob o ponto de vista de normas e legislações vigentes, que todas as pessoas consigam utilizar o ambiente com segurança, conforto e autonomia.

Para que isto seja possível, é importante conhecer as necessidades das pessoas com deficiência, sua opinião e as dimensões que as mesmas consideram relevantes. Portanto, para trabalhos futuros, evidencia-se a necessidade de confrontar os dados técnicos obtidos a partir das planilhas de acessibilidade, utilizadas na visita exploratória, com a opinião deste grupo de indivíduos, o que permitirá relacionar o ponto de vista técnico com aquele oriundo a partir da visão do usuário do espaço.

\section{REFERÊNCIAS}

ABNT NBR 9050. Acessibilidade a edificações, mobiliário, espaços e equipamentos urbanos. Rio de Janeiro: ABNT, 2015. $105 p$.

ANDRADE, Isabela Fernandes. Sistema informacional para a orientação espacial em terminais aeroportuários a partir das estratégias adotadas pelos indivíduos. 2016. 378f. Tese (Doutorado em Arquitetura e Urbanismo) - Programa de pósgraduação, Universidade Federal de Santa Catarina, Florianópolis.

BRASIL. Lei № 10.671 de 15 de maio de 2003. Estatuto de defesa do torcedor, 2003.

BROMBILLA, Douglas de Castro. Evacuação Emergencial em Locais de Reunião de Público: Caso de Estádios de Futebol Brasileiros. 2014. 235f. Dissertação (Mestrado em Arquitetura e Urbanismo) - Programa de pós-graduação, Universidade Federal de Santa Catarina, Florianópolis.

DISCHINGER, M.; BINS ELY, V. H. M.; PIARDI, S. M. D. G. Promovendo acessibilidade espacial nos edifícios públicos: programa de acessibilidade às pessoas com deficiência ou mobilidade reduzida nas edificações de uso público. 1.ed. Florianópolis: Ministério Público de Santa Catarina, 2012. 136p.

ENSSLIN, L.; ENSSLIN, S. R.; PACHECO, G. C. Um estudo sobre segurança em estádios de futebol baseado na análise bibliométrica da literatura internacional. Revista Perspectivas em Ciência da Informação. v. 17, n. 2, p. 71-91. 2012.

ESPORTE CLUBE PELOTAS. Estádio Boca do Lobo - História. Disponível em: http://ecpelotas.com.br/estadio-boca-do-lobo/. 2018.

GOSLING, M. S.; SILVA, J. A.; MENDES, J.; COELHO, M. F.; BRENER, I. Tourist experience in museums: perceptions of managers and visitors. Tourism and Management Studies, v. 12, n. 2, p. 107-116, 2016.

PARAMIO-SALCINES, J. L.; KITCHIN, P. J.; DOWNS, P. Promoting universal accessibility for disabled and older fans to European stadia: A Holistic Journey Sequence Approach (HOPES). Managing Sport Business, n. 27, p. 530-560, 2018.

PINTO, C. F. M.; DORNELES, V. G. O walkthrough na avaliação da acessibilidade espacial em um centro de saúde em Florianópolis. In: VII Encontro Nacional de Ergonomia do Ambiente Construído / VIII Seminário Brasileiro de Acessibilidade Integral, v. 4, n. 2, 2018.

RODEGHIERO NETO, I.; ZANCHIN, M.; BROMBILLA, D. C.; FRANZ, L. A. S.; ANDRADE, I. F. Avaliação das condições de orientação espacial, sob a ótica da segurança, em um ambiente universitário. ERGODESIGN \& HCl, v. 7, p. 53-65, 2020.

SANTOS, R. S.; ZOBOLI, F.; RODRIGUES, C.; FELISBERTO, S. B. Acessibilidade de cadeirantes em um equipamento específico de lazer: o estádio de futebol Batistão na cidade de Aracaju/SE. Licere, v. 20, n. 3, 2017.

SILVA, T. N. R.; SILVA, A. L. R.; CAETANO, V. O.; SILVESTRINI, G. A.; MENEGON, N. L. Passageiros com deficiência visual no transporte aéreo: avaliação da acessibilidade em aeroportos. Cadernos Brasileiros de Terapia Ocupacional, 2019. 


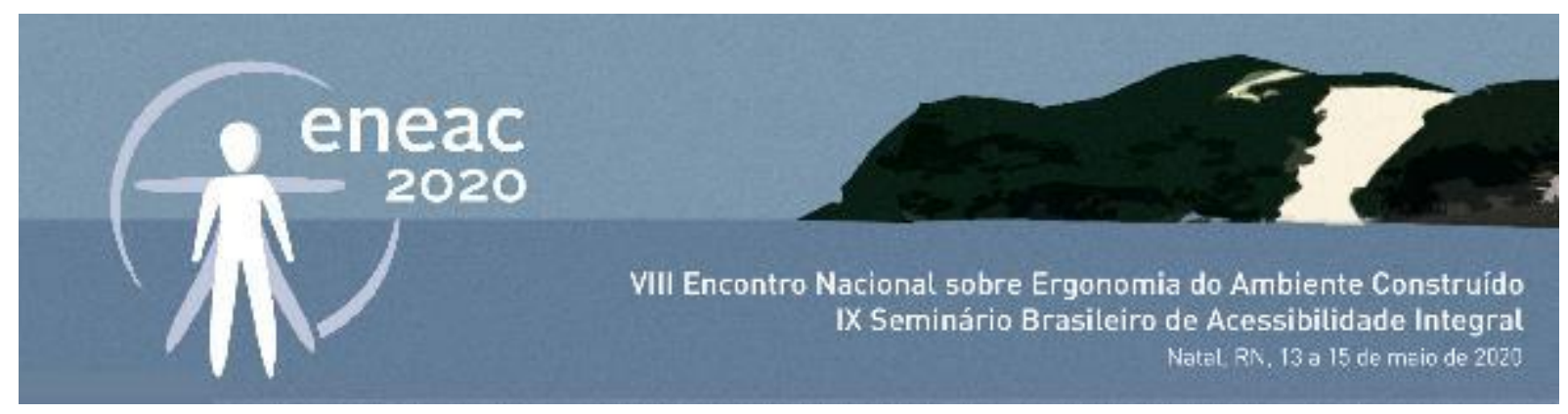

VAN WEE, B. Accessible accessibility research challenges. Journal of Transport Geography, n. 51, p. 9-16, 2016.

YAZIGI, S.; RESENDE, A. E.; YAZIGI, R. Accessibility in Soccer Stadiums: Infrastructure and Organization in Support of People with Reduced Mobility - A Use Analysis. Procedia Manufacturing of 6th International Conference on Applied Human Factors and Ergonomics (AHFE 2015), v. 3, p. 5557-5561, 2015. 